\title{
Epoxidized methyl ricinoleate bio-plasticizer with a pendant acetate ester for PVC artificial material: circumventing existing limit on achievable migration resistance
}

Siyu Pan ${ }^{1}$, Delong Hou², Gaofu Yang², Qiuping Xie', Sunxian Yan' , Qi Zeng ${ }^{1}$, Zhonghui Wang ${ }^{1}$, Yi Chen ${ }^{1 *}$ and Haojun Fan ${ }^{2}$

\begin{abstract}
Processing polyvinyl chloride (PVC) artificial material requires plasticizer that softens the PVC coating. Currently, utilizing unsaturated fatty acid methyl esters to obtain epoxidized fatty acid methyl ester (EFAME) bio-plasticizers constitutes an environmentally responsible solution to substitute conventional ortho-phthalates that are endocrine disruptors or probable carcinogens. However, commercial EFAMEs, even with the highest epoxy value (ca. 5.5-5.8\%) so far, still suffer from fast leaching from the PVC matrix, burdening the environment and shortening lifespan of the artificial material. Here, we report a proof-of-principle demonstration of a new strategy to obtain migration-resistant EFAME that harnesses the midchain hydroxyl of methyl ricinoleate and covalently attachment of a pendant acetate ester. Despite a low epoxy value (3.0\%), the engineered bio-plasticizer displays significantly suppressed migration in multiple scenarios compared with one conventional EFAME with much higher epoxy value (5.8\%). Circumventing the limit confronting previous strategy that highlights the sole contribution of epoxy value to achievable migration resistance, the rationale herein may provide guidance for designing new EFAMEs with comparable performance to ortho-phthalates, thus bringing the old and oft-maligned PVC artificial material industry one step closer to sustainability.
\end{abstract}

Keywords: Plasticizer, Castor oil, Epoxidized fatty acid methyl ester, Migration resistance, Polyvinyl chloride, Artificial material

\section{Introduction}

Among various genuine leather substitutes, polyvinyl chloride (PVC) artificial material, by virtue of its excellent abrasion resistance, strength, toughness, and chemical resistance [1], has attained a high level of popularity ever since its debut in 1930s. As the new millennium unfolds, however, potential ecological risks of PVC resin itself and some auxiliaries have evoked considerable discussion over the future role of PVC artificial material. Plasticizer, one indispensable auxiliary for processing PVC coating, softens the resin to impart flexibility and bendability. Ortho-phthalates are currently the most

\footnotetext{
* Correspondence: chenyi_leon@scu.edu.cn

${ }^{1}$ Key Laboratory of Leather Chemistry and Engineering of Ministry of Education, Sichuan University, Chengdu 610065, People's Republic of China Full list of author information is available at the end of the article
}

commonly used plasticizer for PVC artificial material. Over the past decade, evolving legislative restriction worldwide on ortho-phthalates that have been recognized potentially carcinogenic and endocrine-disrupting has stimulated great interest in bio-based alternatives that are renewable and display little or no adverse effects to human health. Of many bio-plasticizers, epoxidized fatty acid methyl esters (EFAMEs) are enjoying a surge of interest in PVC artificial material industry due to their high plasticizing efficiency [2], renewability [3, 4], degradability $[3,5]$, and low cost $[3,6]$. However, in comparison with ortho-phthalates and high-molecularweight epoxidized soybean oil, EFAMEs, usually obtained from unsaturated fatty acid methyl esters, tend to leach out from the PVC matrix [7], burdening the environment and shortening lifespan of the end-products. For 
decades, researchers have always believed that it is the number of polar epoxy groups that determines the extent of interaction between PVC and EFAME bioplasticizers, and thus, their migration rate from the plastic. Accordingly, considerable efforts have been made to enhance the epoxy value of EFAMEs [8], in an attempt to obtain alternatives with comparable performance to ortho-phthalates. Unfortunately, even with the highest epoxy value (ca. 5.5-5.8\%) so far, EFAME bioplasticizers still display a migration rate approximately tenfold faster than ortho-phthalates [9], making them far from reliable alternatives that facilitate phaseout and replacement of ortho-phthalates.

Indeed, a closer examination of the chemical structure of other plasticizers with suppressed migration reveals a potential solution to the aforementioned limit confronting conventional strategy that highlights the sole contribution of epoxy value to achievable migration resistance. 1,2-cyclohexane dicarboxylic acid diisononyl ester, a non-phthalate plasticizer with comparable performance to ortho-phthalates, does not have any epoxy group at all; instead, it possesses two ester moieties interacting strongly with PVC matrix. Usually, one EFAME molecule only contains one ester group. Thus, we envision that increasing the number of ester that exhibits higher polarity and stability than epoxy ring may be more efficient in promoting molecular-level affinity of EFAMEs to polar PVC chains. Moreover, if the extra ester hangs off from the EFAME as a pendant, the branched plasticizer and PVC are supposed to intertwine, rather than simply intermingle, with each other, contributing to further suppressed migration.

Here, we report a proof-of-principle demonstration of how to make an EFAME bio-plasticizer for PVC artificial material migration-resistant by utilizing a pendant acetate ester strategy. The feedstock employed herein is castor oil, a natural non-edible oil, categorized by United States Food and Drug Administration (FDA) as "generally recognized as safe and effective" [10]. This feedstock is unique, in that approximately $90 \%$ of its fatty acid chains are ricinoleates, featuring both an epoxidizable, cis-double bond between the $9^{\text {th }}$ and $10^{\text {th }}$ carbon atoms, and an extra hydroxyl on the $12^{\text {th }}$ carbon. By esterification with acetic anhydride, the midchain hydroxyl can be converted into an extra acetate ester, making methyl ricinoleate branched, and more importantly, much more polar. Both comparative experiments and molecular simulation reveal that the engineered bio-plasticizer, in spite of a relatively low epoxy value (3.0\%), displays significantly suppressed migration than one ordinary, highly epoxidized EFAME with an epoxy value of $5.8 \%$. Circumventing the existing limit on achievable migration resistance, the underlying rationale in the present study may enable new EFAMEs with comparable performance to ortho-phthalates, thus bringing the old and oftmaligned PVC artificial material industry one step closer to sustainability.

\section{Experimental}

\subsection{Materials}

Castor oil $\left(\mathrm{CO}\right.$, iodine value $\left.=80 \mathrm{gI}_{2} / 100 \mathrm{~g}\right)$, di-(2-ethylhexyl) phthalate (DEHP, 99\%), phosphoric acid (85\%), acetic anhydride (98.5\%), formic acid (88\%), and hydrogen peroxide $(50 \%)$ were purchased from Chron Chemicals Co., Ltd. (Chengdu, China). Suspension PVC resin (SG-5, average polymerization degree 1150-1000) and a mixed metal stabilizer composed of calcium stearate and zinc stearate were supplied by Jinlu Resin Co., Ltd. (Chengdu, China). Commercial EFAME with an epoxy value of ca. 5.8\% was obtained from Hebei Jingu Plasticizer Co., Ltd. As specified by the supplier, this EFAME plasticizer was synthesized from unsaturated fatty acid methyl esters with an average iodine value of $110 \mathrm{gI}_{2} /$ $100 \mathrm{~g}$. Ultrapure water (resistivity $=18.2 \mathrm{M} \Omega \cdot \mathrm{cm}$ at $25^{\circ} \mathrm{C}$ ) was obtained from a Millipore Synergy water purification system. All reagents were used without further purification unless otherwise stated.

\subsection{Synthesis of epoxidized methyl ricinoleate with a pendant acetate ester (EMRA)}

Methyl ricinoleate (MR) was synthesized by transesterification of $\mathrm{CO}$ triglycerides with methanol. Briefly, into a $250 \mathrm{~mL}$ flask were added $100 \mathrm{~g}$ of $\mathrm{CO}$ and $1.5 \mathrm{~g}$ of potassium hydroxide dissolved in $33 \mathrm{~g}$ of methanol. The mixture was stirred at $40{ }^{\circ} \mathrm{C}$ for $1 \mathrm{~h}$. Sulfuric acid was then added in a stepwise manner, followed by washing the neutralized mixture with deionized water three times. Finally, the combined organic phases were dried under reduced pressure at $60^{\circ} \mathrm{C}$, affording MR in ca. $95 \%$ yield as a pale-yellow oil.

Subsequently, the midchain hydroxyl in MR was esterified with acetic anhydride as per the following procedure. $100 \mathrm{~g}$ of MR and $40 \mathrm{~g}$ of acetic anhydride were charged into a $250 \mathrm{~mL}$ flask with a reflux condenser. The mixture was stirred at $150^{\circ} \mathrm{C}$ for $1.5 \mathrm{~h}$ under nitrogen atmosphere. Upon completion of the reaction, acetic acid was removed by distillation under reduced pressure. The crude product was extensively washed with deionized water, followed by distillation under reduced pressure at $60^{\circ} \mathrm{C}$, resulting in methyl ricinoleate with a pendant acetate ester (MRA) in ca. 93\% yield.

The unsaturated double bond in MRA was finally epoxidized to obtain the final EMRA. First, $100 \mathrm{~g}$ of MRA, $5 \mathrm{~g}$ of formic acid, and $0.5 \mathrm{~g}$ of phosphoric acid were added to a flask and stirred at $50{ }^{\circ} \mathrm{C}$. Then, $40 \mathrm{~g}$ of hydrogen peroxide was added dropwise into the mixture at a constant rate over a period of $2.5 \mathrm{~h}$ by using an automatic dripping apparatus. After that, the mixture 
was continuously stirred at $50^{\circ} \mathrm{C}$ for another $3 \mathrm{~h}$, followed by separation of the organic layer which was then washed successively with $3 \%(\mathrm{w} / \mathrm{w})$ sodium bicarbonate aqueous solution and deionized water until it was acid free. Finally, EMRA with a yield of ca. 95\% was obtained by drying in a vacuum oven at $80^{\circ} \mathrm{C}$ until a constant weight. The synthesis procedure and chemical structure of EMRA were illustrated in Scheme 1.

\subsection{Preparation of plasticized PVC membranes}

A series of PVC membranes plasticized with EMRA, EFAME, or DEHP at a fixed plasticizer content were prepared. In brief, $100 \mathrm{~g}$ of PVC powder, $50 \mathrm{~g}$ of plasticizer, and $2 \mathrm{~g}$ of stabilizer were first mixed at room temperature. The mixture was then plasticized by a tworoll mill (CH-0201, Chuanghong Instrument Equipment Co., Ltd., Dongguang, China) with a rotate speed of $12 \mathrm{r}$ / $\mathrm{min}$ at $150^{\circ} \mathrm{C}$ for $15 \mathrm{~min}$, yielding a transparent and uniform membrane with an average thickness of $0.5 \mathrm{~mm}$. All the plasticized PVC membranes were conditioned in a desiccator containing silica gel for 7 days prior to characterization.

\subsection{Characterization}

The acid value, iodine value, epoxy value, flash point, and hydroxyl number of the synthesized products were determined according to Chinese Standards GB/T 1668-2008 [11], GB/T 1676-2008 [12], GB/T 16772008 [13], GB/T 1671-2008 [14], and international standard ISO 14900:2001 [15], respectively, and the results summarized in Table 1.

Fourier transform infrared (FT-IR) spectra were collected at ambient temperature using a Nicolet iS10 FTIR spectrometer (Thermo Scientific, United States) over a wavenumber range from 400 to $4000 \mathrm{~cm}^{-1}$ after 32 scans at a resolution of $2 \mathrm{~cm}^{-1}$. Nuclear magnetic resonance (NMR) spectra were recorded by a NMR spectrometer (AV11-600MH, Bruker, Swiss) in the Fourier transform mode at $25^{\circ} \mathrm{C}$ with deuterated chloroform
$\left(\mathrm{CDCl}_{3}-\mathrm{d}_{6}, 99.9\right.$ atom\% $\left.\mathrm{D}\right)$ as deuterium reagent and tetramethylsilane (TMS) as the internal standard. Gas chromatography-mass spectrometry (GC-MS) (Agilent Techn., Inc., 7890A/5975C, Rxi-5MS column) was employed to analyze the composition of MR, MRA, and EMRA. To ensure good separation of the analytes, the initial column temperature was held at $60^{\circ} \mathrm{C}$, and then to $160{ }^{\circ} \mathrm{C}$ at $10^{\circ} \mathrm{C} / \mathrm{min}$, and finally increased to $280^{\circ} \mathrm{C}$ at $3{ }^{\circ} \mathrm{C} / \mathrm{min}$. Helium (99.999\% pure) was used as carrier gas at a flow rate of $3.0 \mathrm{~mL} / \mathrm{min}$. MS data was obtained with an ion source temperature of $200^{\circ} \mathrm{C}$. The mass range from $m / z=22$ to 600 was scanned, and the components were identified by comparing the experimental mass spectra with those references available in NIST08.LIB. Differential scanning calorimetric (DSC) analysis was performed on a NETZSCH DSC 200 PC analyzer purged with nitrogen gas and quenched with liquid nitrogen. The sample was scanned from -150 to $150^{\circ} \mathrm{C}$ with a heating rate of $10^{\circ} \mathrm{C} / \mathrm{min}$ under a $60 \mathrm{~mL} / \mathrm{min}$ nitrogen atmosphere.

Plasticizer exudation was determined by mass change of a plasticized PVC membrane with a diameter of 80 $\mathrm{mm}$ that were sandwiched between two pieces of filter paper. The assembly was pressed by a flat bottom block $(500 \mathrm{~g})$, and placed at $70 \pm 1^{\circ} \mathrm{C}$ for $72 \mathrm{~h}$ or $0 \pm 1^{\circ} \mathrm{C}$ for $24 \mathrm{~h}$. After that, the PVC membranes were conditioned at room temperature for $8 \mathrm{~h}$ before their mass changes were recorded. A fogging tester (Thermo Scientific Haake Fogging Tester, P2-FOG, PHOENIX II) was employed to evaluate the volatility of the plasticizers from PVC membranes at $100 \pm 0.5^{\circ} \mathrm{C}$ for $16 \mathrm{~h}$ according to ISO 6452:2000 [16] and DIN 75201 [17]. To determine resistance of the plasticizers to extraction, the plasticized PVC membranes $(50 \mathrm{~mm} \times 50 \mathrm{~mm} \times 0.5 \mathrm{~mm})$ were soaked in distilled water, aqueous ethanol $(95 \%, \mathrm{v} /$ v), or petroleum ether at $23 \pm 2{ }^{\circ} \mathrm{C}$ for $24 \mathrm{~h}$. Subsequently, the PVC membranes were dried at $30^{\circ} \mathrm{C}$ for 24 $\mathrm{h}$, and then placed in a desiccator at room temperature for $72 \mathrm{~h}$ before re-weighing and calculating their mass

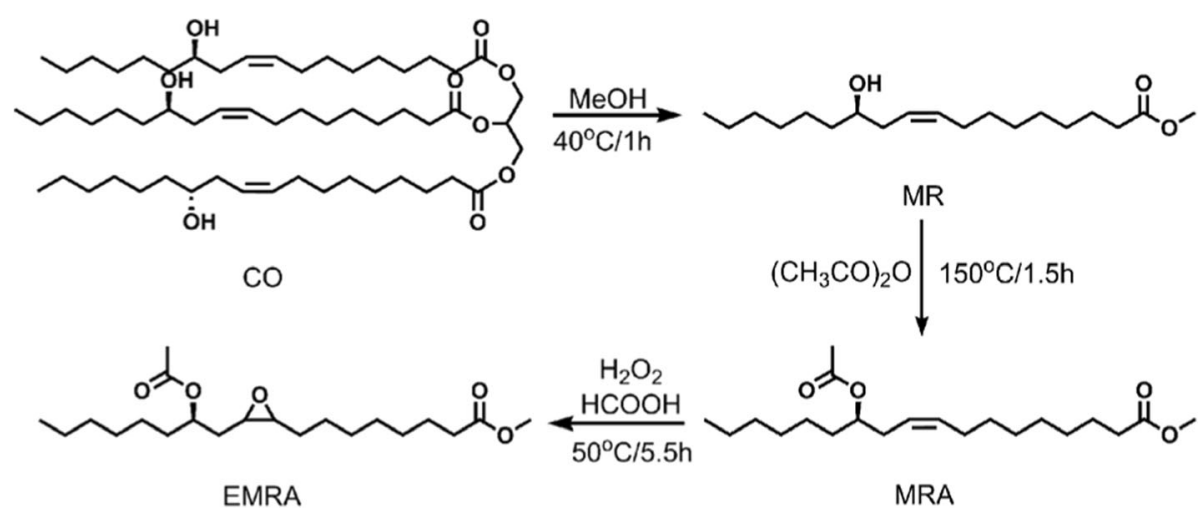

Scheme 1 Synthesis procedure and chemical structure of EMRA 
Table 1 Physicochemical parameters of EMRA and corresponding intermediates

\begin{tabular}{llllll}
\hline Sample & Acid value $(\mathrm{mgKOH} / \mathrm{g})$ & lodine value $\left(\mathrm{gl}_{2} / 100 \mathrm{~g}\right)$ & Hydroxyl number $(\mathrm{mgKOH} / \mathrm{g})$ & Epoxy value $(\%)$ & Flash point $\left({ }^{\circ} \mathrm{C}\right)$ \\
\hline CO & 0.3 & 85 & 162 & $\mathrm{n} / \mathrm{a}$ & $\mathrm{n} / \mathrm{a}$ \\
MR & 0.5 & 85 & 161 & $\mathrm{n} / \mathrm{a}$ & $\mathrm{n} / \mathrm{a}$ \\
MRA & 0.5 & 74 & 0 & $\mathrm{n} / \mathrm{a}$ & $\mathrm{n} / \mathrm{a}$ \\
EMRA & 0.5 & 5 & $\mathrm{n} / \mathrm{a}$ & 3.0 & 204 \\
EFAME & 0.5 & 3 & $\mathrm{n} / \mathrm{a}$ & 5.8 & 186 \\
\hline
\end{tabular}

changes relative to the original condition. The reported data were mean of triplicate samples for each measurement.

\subsection{Simulation details}

Molecular dynamics (MD) simulations were carried out using Materials Studio 8.0 commercial software (Accelry Inc., San Diego, CA), where the interatomic interactions were described by using the COMPASS force field. First, one atactic PVC chain with 100 repeat units and ten plasticizer molecules were enclosed in a cubic cell by the amorphous cell module at $300 \mathrm{~K}$, based on the "self-avoiding" random-walk method of Theodorou and Suter [18]. Periodic boundary conditions were applied in all three directions to prevent finite-size effects. Subsequently, the cell was subject to geometry optimization using the Smart algorithm in Forcite module with a fine convergence threshold, followed by an annealing procedure in which the system was heated from $300 \mathrm{~K}$ to $500 \mathrm{~K}$ at intervals of $50 \mathrm{~K}$ and then cooled back to $300 \mathrm{~K}$ at intervals of $10 \mathrm{~K}$. At each temperature interval, a $200 \mathrm{ps}$ NPT dynamics ( $P=1$ bar) was carried out with a time-step of $1 \mathrm{fs}$. Andersen and Berendsen algorithms were employed to maintain a constant temperature and pressure, respectively. The atom-based technique was employed to calculate the van der Waals potential, truncated for atom pairs with a distance larger than $11.5 \AA$. This cutoff distance was always smaller than half of the cell length to avoid self-image interactions. The truncation was applied using a quantic switching function with a spline width of $1.0 \AA$. A buffer width of $0.5 \AA$ was specified to generate the neighbor list. Coulombic interactions were calculated using the Ewald summation method with an Ewald accuracy of $0.001 \mathrm{kcal} /$ mol and an update width of 1.0. After the annealing procedure, the assembly was equilibrated at $450 \mathrm{~K}$ for $10 \mathrm{~ns}$ using NPT ( $P=1$ bar) ensemble before successive positions of the plasticizers were computed as a function of time by solving Newton's equations. Finally, self-diffusion coefficients were calculated from the slope of the MSD ( $t$ ) plot according to Einstein relation, as described in our previous publications $[19,20]$.

\section{Results and discussion}

PVC artificial material is essentially a knit or woven fabric coated with a flexible plastic made from PVC resin and additives such as plasticizers to manipulate its softness and texture. Since ortho-phthalates, the most commonly used plasticizer, have been recognized potentially carcinogenic and endocrine-disrupting, PVC artificial material has currently been under intense legislative and press scrutiny. Thus, developing alternative plasticizer with comparable performance to ortho-phthalates necessitates urgent action. Of many alternatives, EFAMEs, usually obtained from unsaturated fatty acid methyl esters, are promising and being utilized in PVC artificial material industry on a large scale. Despite their advantages over ortho-phthalates and high-molecular-weight epoxidized soybean oil, EFAMEs are suffering from fast leaching from the PVC coating, making them far from ideal substitutes to ortho-phthalates.

To provide an alternative solution to this problem, in the present study, taking advantage of the unique midchain hydroxyl in castor oil, epoxidized methyl ricinoleate bearing a pendent acetate ester as potential bioplasticizer for manufacturing PVC artificial material was synthesized via a three-step method. The structure and composition of each intermediate and the final product were systematically characterized by multiple techniques. The FT-IR spectra of CO, MR, MRA, and EMRA were compared in Fig. 1. From the spectra of $\mathrm{CO}$ and MR, a strong and broad absorption band peaking at about $3372 \mathrm{~cm}^{-1}$ was detected, corresponding to the $\mathrm{O}-\mathrm{H}$ stretching vibration of hydroxyl. After esterification with acetic anhydride, this characteristic absorption disappeared completely, indicating the hydroxyl-bearing MR was successfully converted into MRA. Since methylene displayed undisturbed characteristic absorption band peaking at $2856 \mathrm{~cm}^{-1}$ with constant relative intensity in MR and MRA, employing methylene as internal standard to monitor the esterification reaction, and thus, structural derivation from MR to MRA, was reasonable. Relative to that of methylene, the absorption intensities of carbonyl $(\mathrm{C}=\mathrm{O})$ and $\mathrm{C}-\mathrm{O}$ stretching peaks increased after esterification. To be specific, the intensity ratio of the FT-IR absorption at $1739(\mathrm{C}=\mathrm{O})$ and $1240 \mathrm{~cm}^{-1}(\mathrm{C}$ O) to that at $2856 \mathrm{~cm}^{-1}\left(\mathrm{CH}_{2}\right)$ increased from 1.2 and 0.4 to 1.53 and 1.39 , respectively. This was because the midchain hydroxyl in MR had reacted with acetic anhydride, yielding more aliphatic esters. Moreover, the absorption band peaking at about $3007 \mathrm{~cm}^{-1}$ corresponded 


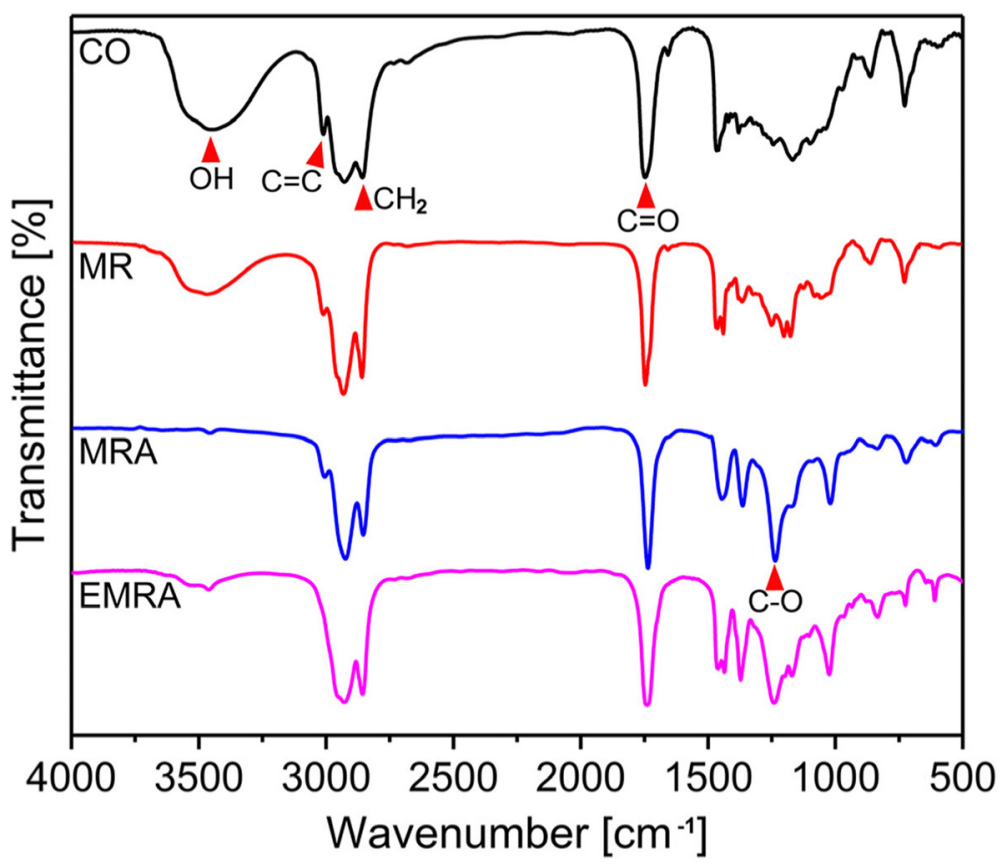

Fig. 1 FT-IR spectra of $C O, M R, M R A$, and EMRA

to the stretching vibration of double bonds, which could be detected simultaneously in CO, MR, and MRA. A small portion of these double bonds were consumed over the esterification procedure, manifested as a slight decrease of iodine value in MRA relative to MR and CO (Table 1). Upon epoxidation, the double bond-derived absorption disappeared completely, accompanied with a significant decrease of iodine value from approximately $74 \mathrm{gI}_{2} / 100 \mathrm{~g}$ in MRA to $5 \mathrm{gI}_{2} / 100 \mathrm{~g}$ in EMRA. Unfortunately, owing to band overlapping in the region of interests, the characteristic absorption corresponding to the oxirane ring in epoxy group could not be identified distinctly in the spectrum of EMRA. Nevertheless, chemical titration revealed that the epoxy value of the final EMRA was approximately $3.0 \%$, significantly lower than that of the commercial EFAME employed in this study displaying an epoxy value as high as $5.8 \%$.

Analyzing the NMR spectra of the above-mentioned samples further revealed covalent attachment of a pendent acetate ester in EMRA. The ${ }^{1} \mathrm{H}$ NMR spectra of the feedstock (CO), two intermediates (MR and MRA), and EMRA were plotted in Fig. 2. The experimental spectrum of $\mathrm{CO}$ was found in good agreement with previously disclosed result [21]; the observed resonances could be unequivocally assigned to an individual or a category of protons in $\mathrm{CO}$ (Fig. 2a). In comparison with $\mathrm{CO}$, a new, strong resonance signal peaking at around $3.59 \mathrm{ppm}$ appeared in the ${ }^{1} \mathrm{H}$ NMR spectrum of MR (Fig. 2b), at the expense of the resonance signals corresponding to the tertiary and methylene protons in glycerin moiety. This new signal could be ascribed to the terminal $-\mathrm{OCH}_{3}$ protons after transesterification with methanol. Upon esterification using acetic anhydride, covalent attachment of a pendant acetate ester could be verified by appearance of a strong resonance signal peaking at around $1.96 \mathrm{ppm}$ (Fig. 2c), derived from the terminal $-\mathrm{CH}_{3}$ protons in acetate ester. Meanwhile, the pendant altered the chemical microenvironment of adjacent protons, and thus the signals at around 1.37-1.41, 2.12-2.16, 3.51-3.57 ppm in MR all exhibited a slight downfield shift in MRA. In the ${ }^{1} \mathrm{H}$ NMR spectrum of EMRA (Fig. 2d), the double bond-associated multiplets ranging from 5.2-5.4 ppm disappeared, whereas two resonance signals derived from the tertiary protons in oxirane ring were visible at $2.79-2.83$ and $2.87-2.93 \mathrm{ppm}$, suggesting successful epoxidation of MRA. In addition, the resonance signals at around 1.65-1.80 and 1.96$2.06 \mathrm{ppm}$ became more complex in EMRA, which might be ascribed to diversification of proton chemical microenvironment following epoxidation.

In addition, identifying the composition in MR, MRA, and EMRA further revealed the nature and extend of each reaction leading to EMRA. The gas chromatograms of MR, MRA, and EMRA were illustrated in Fig. 3. Using the Probability Based Matching (PBM) algorithm against NIST08 mass spectral library, the molecular structure corresponding to each chromatogram peak in Fig. 3 was identified, and the results were tabulated in Table 2. In the case of MR (Fig. 3a), five components could be discerned, three of which being unsaturated 


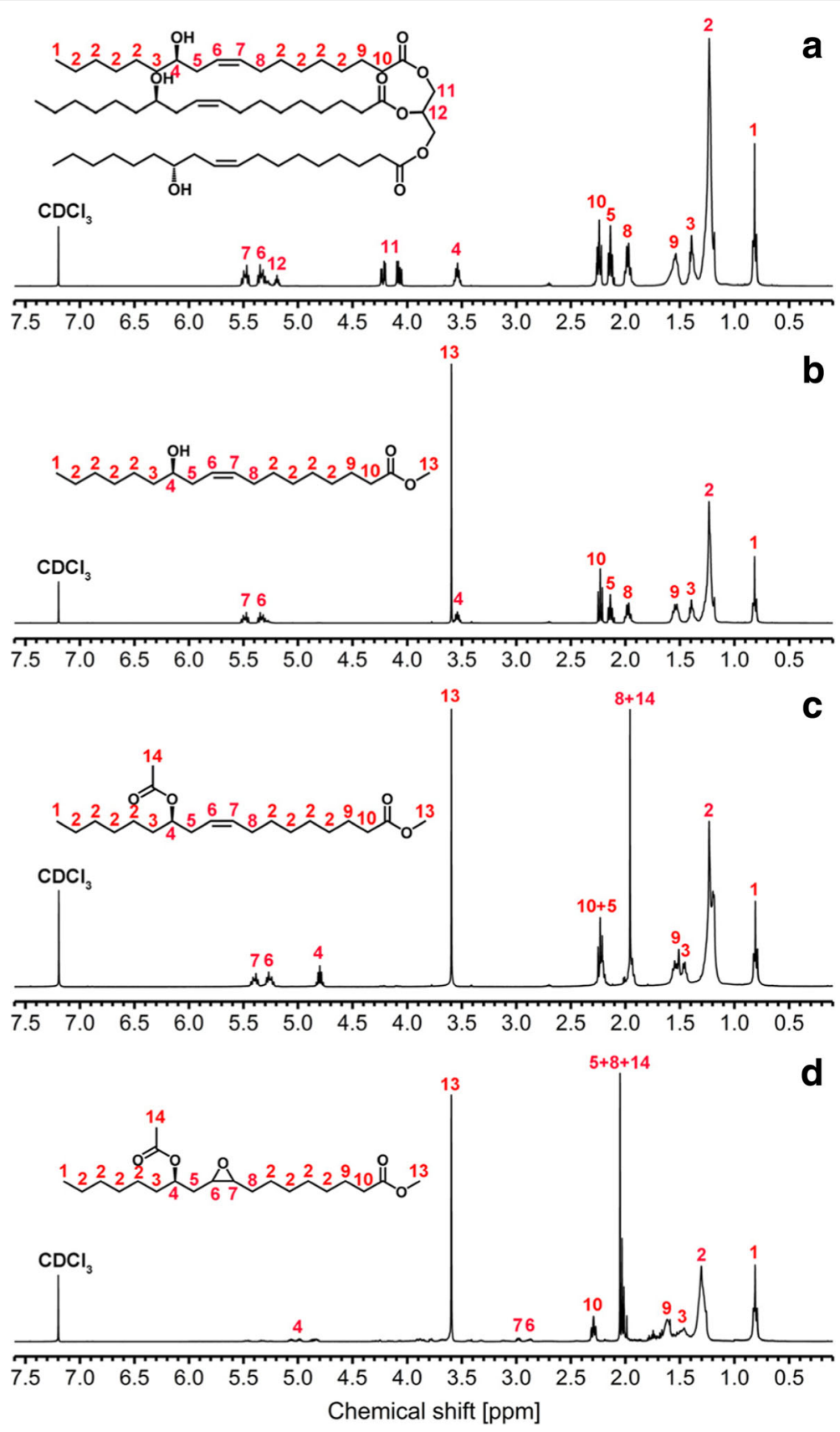

Fig. $2{ }^{1} \mathrm{H}$ NMR spectra of a CO, b MR, c MRA, and d EMRA

fatty acid methyl esters while the remaining two being saturated. Clearly, the component with the retention time of 38.4 min dominated, which was identified as methyl ricinoleate. Upon esterification using acetic anhydride, the chromatogram peak at $38.4 \mathrm{~min}$ disappeared completely, while a new peak with comparable intensity and area was detected at approximately $40.4 \mathrm{~min}$ in MRA (Fig. 3b). By comparing the mass spectrum of this new component against NIST08, it was identified as methyl ricinoleate bearing a pendant acetate ester, or methyl acetyl ricinoleate, indicating complete conversion of methyl ricinoleate to the expected intermediate. Meanwhile, the other four components with retention time $<34$ min remained almost unchanged, suggesting the site-specific nature of the esterification reaction. Since saturated fatty acid methyl esters are resistant to epoxidation, the components peaking at 27.3 and 33.3 min remained almost unchanged after epoxidation. Instead, the chromatogram peaks corresponding to the unsaturated components either disappeared completely 


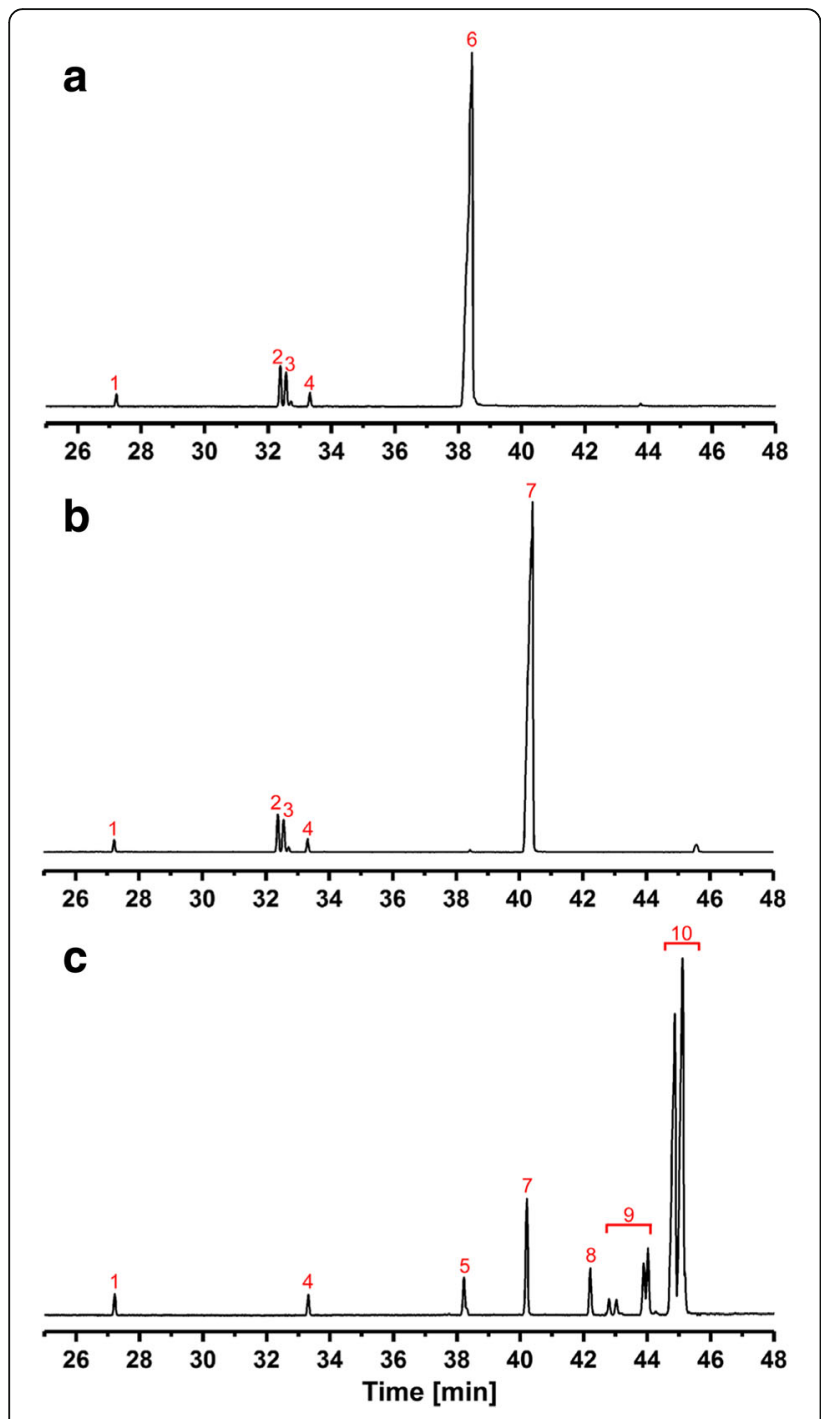

Fig. 3 Gas chromatograms of a MR, b MRA, and c EMRA (retention time $=32.4$ and $32.6 \mathrm{~min}$ ), or experienced a significant decrease in concentration (retention time $=$ $38.4 \mathrm{~min}$ ). Accordingly, a series of new chromatogram peaks associated with epoxidized fatty acid methyl esters were discerned in the retention time range of 42-46 min in EMRA. The dominating component in the final product was found to be EMRA, or epoxidized methyl acetyl ricinoleate, as expected. Furthermore, by comparing the area of MRA-associated peak (retention time $=40.4 \mathrm{~min}$ ) in Fig. $3 \mathrm{~b}$ and c, it was confirmed that $89 \%$ of the MRA intermediate had been converted into EMRA.

For decades, researchers have long believed that enhancing the epoxy value of EFAME bio-plasticizers that facilitate molecular-level interaction between EFAME and polar PVC chains is the only way to suppress their leaching from PVC matrix. Accordingly, highly unsaturated feedstocks are preferred in the synthesis of EFAMEs that may afford bio-plasticizers with high epoxy value. This strategy, however, suffers from limitations, as exemplified by unavailability and high cost of the feedstocks, and more importantly, cross-linking between individual plasticizer molecules leading to high viscosity [22]. Now, commercial EFAMEs usually possess an epoxy value not exceeding 5.8\%. Nevertheless, even with the highest epoxy value so far, EFAMEs still display a migration rate approximately tenfold faster than ortho-phthalates [9], making them far from reliable alternatives. With an extra acetate ester hanging off from EMRA as a pendant, EMRA should exhibit improved affinity or entanglement to polar PVC chains, suppressing their migration from the PVC matrix. This conclusion was demonstrated herein by evaluating EMRA migration from plasticized PVC membranes in multiple scenarios. Fogging resistance of the plasticized PVC membranes were first determined to evaluate plasticizer migration at elevated temperature. As shown in Fig. 4a, despite a high epoxy

Table 2 Composition of MR, MRA, and EMRA identified by comparing the experimental mass spectra of the components in Fig. 3 against NIST08 mass spectral library

\begin{tabular}{|c|c|c|c|c|c|c|c|}
\hline \multirow{2}{*}{$\begin{array}{l}\text { Peak } \\
\text { No. }\end{array}$} & \multirow{2}{*}{$\begin{array}{l}\text { Retention } \\
\text { time } \\
\text { (min) }\end{array}$} & \multirow[t]{2}{*}{ Component } & \multirow{2}{*}{$\begin{array}{l}\text { Molecular } \\
\text { formula }\end{array}$} & \multicolumn{3}{|c|}{ Area (\%) } & \multirow{2}{*}{$\begin{array}{l}\text { Matching } \\
\text { degree } \\
(\%)\end{array}$} \\
\hline & & & & $\overline{M R}$ & MRA & $\overline{\text { EMRA }}$ & \\
\hline 1 & 27.3 & Methyl hexadecanoate & $\mathrm{C}_{17} \mathrm{H}_{34} \mathrm{O}_{2}$ & 1.1 & 1.2 & 1.0 & 96 \\
\hline 2 & 32.4 & Methyl linoleate & $\mathrm{C}_{19} \mathrm{H}_{34} \mathrm{O}_{2}$ & 4.2 & 4.2 & & 95 \\
\hline 3 & 32.6 & Methyl oleate & $\mathrm{C}_{19} \mathrm{H}_{36} \mathrm{O}_{2}$ & 4.2 & 4.2 & & 91 \\
\hline 4 & 33.3 & Methyl stearate & $\mathrm{C}_{19} \mathrm{H}_{38} \mathrm{O}_{2}$ & 1.4 & 1.4 & 1.0 & 95 \\
\hline 5 & 38.2 & Methyl 9,10-epoxystearate & $\mathrm{C}_{19} \mathrm{H}_{36} \mathrm{O}_{3}$ & & & 2.2 & 94 \\
\hline 6 & 38.4 & Methyl ricinoleate & $\mathrm{C}_{19} \mathrm{H}_{36} \mathrm{O}_{3}$ & 89.1 & & & 93 \\
\hline 7 & 40.4 & Methyl acetyl ricinoleate & $\mathrm{C}_{21} \mathrm{H}_{38} \mathrm{O}_{4}$ & & 89.0 & 6.3 & 91 \\
\hline 8 & 42.2 & Methyl 9,10:12,13-diepoxystearate & $\mathrm{C}_{19} \mathrm{H}_{34} \mathrm{O}_{4}$ & & & 2.7 & $\mathrm{n} / \mathrm{a}^{\mathrm{a}}$ \\
\hline 9 & $42.8-44.0$ & Other compounds & & & & 5.2 & $n / a$ \\
\hline 10 & $44.9-45.1$ & Epoxidized methyl acetyl ricinoleate & $\mathrm{C}_{21} \mathrm{H}_{38} \mathrm{O}_{5}$ & & & 81.6 & $\mathrm{n} / \mathrm{a}^{\mathrm{a}}$ \\
\hline
\end{tabular}

Indeed, the component 8 and 10 could not be explicitly identified by the NIST08 mass spectral library. However, their structures could be inferred from their retention time and peak area in the gas chromatogram, as well as composition of the feedstock 

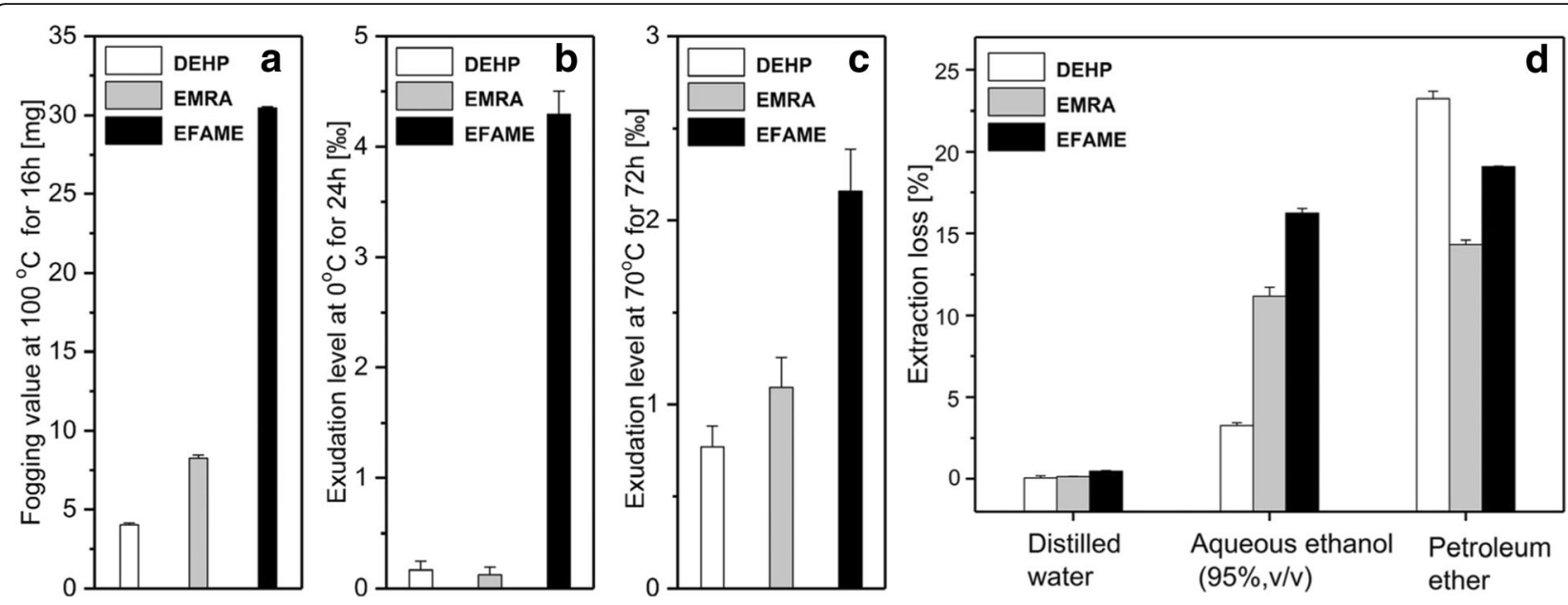

Fig. 4 a Fogging value, and plasticizer exudation level at $\mathbf{b} 0{ }^{\circ} \mathrm{C}$ for $24 \mathrm{~h}$ and $\mathbf{c} 70^{\circ} \mathrm{C}$ for $72 \mathrm{~h}$ of the plasticized PVC membranes. The extraction loss of plasticizers from the PVC membranes in different liquid media was shown in $\mathbf{d}$

value (5.8\%), $30.4 \pm 0.1 \mathrm{mg}$ of EFAME evaporated from the PVC membrane upon heating at $100^{\circ} \mathrm{C}$ for $16 \mathrm{~h}$, significantly higher than that of DEHP and EMRA, which displayed a fogging value of approximately $4.0 \pm 0.1$ and $8.1 \pm 0.2 \mathrm{mg}$, respectively. This result indicated the crucial role played by the pendant acetate ester in suppressing plasticizer migration. Not only at elevated temperature but also in close contact with solid surface can plasticizers leach out of the PVC matrix. According to the results from exudation experiment using two closely contacted filter papers (Fig. 4b and c), one could tell that EMRA was as resistant as DEHP in migration at low temperature $\left(0^{\circ} \mathrm{C}\right)$, or displayed an exudation level comparable to DEHP at high temperature $\left(70^{\circ} \mathrm{C}\right)$. However, the exudation level of EFAME $\left(4.3 \%\right.$ at $0{ }^{\circ} \mathrm{C} ; 2.2 \%$ at $70^{\circ} \mathrm{C}$ ) was found more than 30 times higher than that of EMRA $(0.13 \%)$ at $0{ }^{\circ} \mathrm{C}$, or doubled relative to EMRA $\left(1.1 \%\right.$ o) at $70{ }^{\circ} \mathrm{C}$, even though the latter possessed a much higher epoxy value than the former. In liquid media, migration resistance of the plasticizers became much more complicated, depending on polarity of the media. Herein, distilled water, aqueous ethanol, and petroleum ether were selected to evaluate resistance of the plasticizers to extraction, because they are representatives for solvents with strong-, medium-, and nonpolarity, respectively. Especially in aqueous alcohol and petroleum ether, EMRA displayed higher resistance to extraction compared with ordinary EFAME. These results indicated again that the protruding acetate ester in EMRA facilitated more entanglement with the plastic matrix, or formed stronger interaction with PVC chains than conventional EFAME bearing only one ester group.

The conclusion reached from the aforementioned experiments was further validated by a fully atomistic molecular modeling that reproduced a PVC-plasticizer binary system in which the migration rate of the plasticizers could be theoretically quantified. To this end, accurate simulation of the condensed-phase properties of PVC matrix was crucial, which was validated herein by comparing specific properties estimated from simulations with experimental values. As illustrated in SI Additional file 1: Table S1, the density, Hildebrand solubility parameter, and cohesive energy density of the pure PVC model at $300 \mathrm{~K}$ were $1.381 \pm 0.003 \mathrm{~g} / \mathrm{cm}^{3}, \quad 19.52 \pm 0.14 \quad\left(\mathrm{~J} / \mathrm{cm}^{3}\right)^{0.5}$, and $(3.85 \pm 0.05) \times 10^{8} \mathrm{~J} / \mathrm{m}^{3}$, respectively. These simulated values fell directly within the narrow range of their experimental counterparts, suggesting that the modeling methodology herein acceptably reproduced the condensedphase properties of real-world PVC materials. Subsequently, ten plasticizer molecules were enclosed in the PVC model, and the assembly was equilibrated for $10 \mathrm{~ns}$ using NPT ( $\mathrm{T}=450 \mathrm{~K} ; P=1$ bar) ensemble after annealing. Averaged over all plasticizers and all starting times, the MSD (t) plots of the plasticizer molecules over the NPT dynamics run were obtained, as shown in Fig. 5. In general, the slope of the MSD ( $t$ ) plot reflects mobility of the molecules. Clearly, EFAME intended to migrate more easily than DEHP and EMRA within the PVC model, manifested as a much larger slope than the other two plasticizers. Over the simulation time from 1000 to $5000 \mathrm{ps}$, it was found that the slope of the $\log (\mathrm{MSD})$ vs. $\log (\mathrm{t})$ plots approached unity, indicating a normal diffusion regime, from which the Einstein equation was valid for calculating self-diffusion coefficients of the plasticizers according to the slope of the MSD ( $t$ ) plots. In the case of EFAME, the self-diffusion coefficients were found to be $4.54 \times 10^{-7}$ $\mathrm{cm}^{2} / \mathrm{s}$, three to four times higher than that of DEHP $\left(1.59 \times 10^{-7} \mathrm{~cm}^{2} / \mathrm{s}\right)$ and EMRA $\left(1.22 \times 10^{-7} \mathrm{~cm}^{2} / \mathrm{s}\right)$. These simulation data were in good agreement with previous experimental results that EFAME exhibited fastest migration 

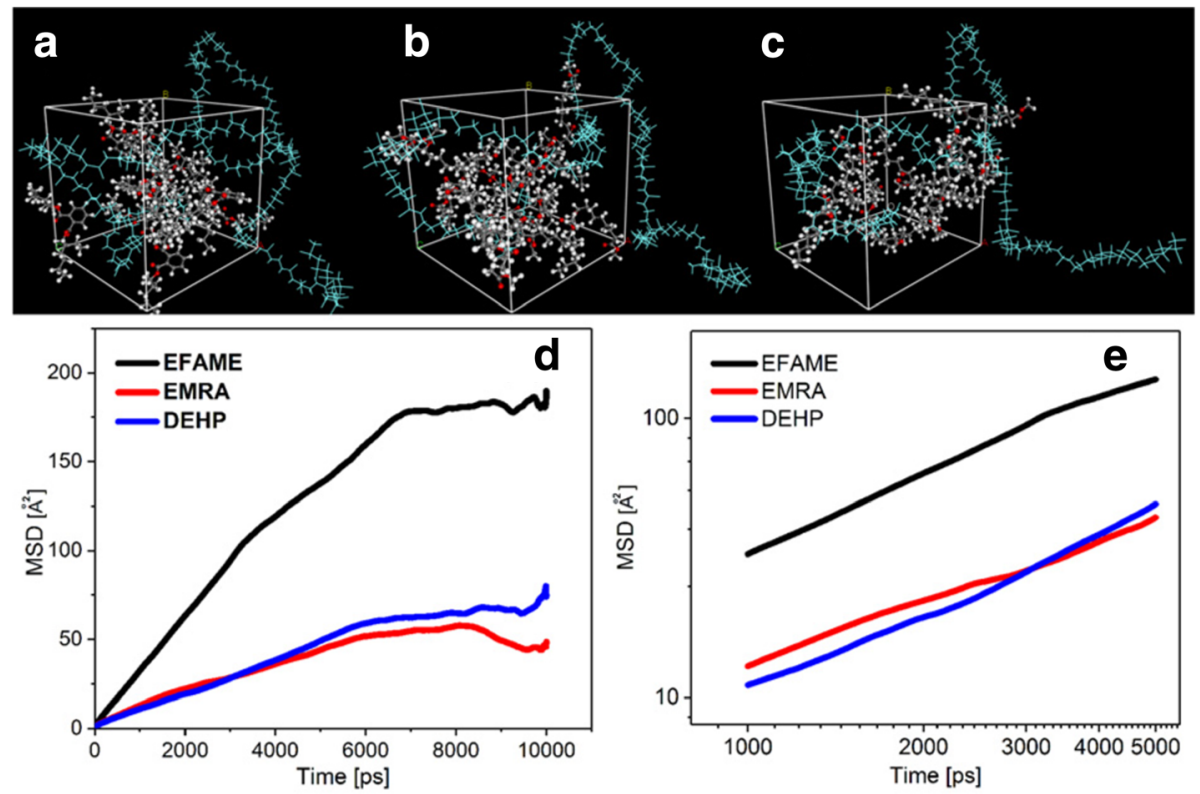

Fig. 5 Three-dimensional amorphous cell of PVC matrix containing ten a DEHP; b EMRA; c EFAME, well-equilibrated at $450 \mathrm{~K}$ by using NPT assemble $(P=1$ bar) after an annealing procedure. $\mathbf{d}$ MSD vs. time plots of the plasticizer molecules over the NPT dynamics run. To illustrate that a normal diffusion regime was reached where the Einstein relation was valid for self-diffusion coefficients calculation, the log (MSD) vs. log (t) plots of the plasticizer molecules in the range of 1000-5000 ps were shown in e. Note that the slope of the log (MSD) vs. log (t) plots in e approached unity

rate among the three plasticizers under consideration. Surprisingly, we found the self-diffusion coefficient of EMRA was slightly lower than that of DEHP, indicating the engineered bio-plasticizer might be more resistant to leaching than DEHP. However, this result contradicted experimental data that revealed the advantage of DEHP over EMRA in migration resistance. We believed that this contradiction appeared because EMRA was indeed a mixture containing a small fraction of saturated fatty acids and linear EFAME that might be subject to migration.

In addition, we also measured the glass transition temperature of the plasticized PVC membranes, from which the plasticizing efficiency of EMRA could be determined. According to the data in SI Additional file 1: Table S2, the glass transition temperature of pure PVC decreased from 87.0 to $-4.0,-25.4$, and $-27.7^{\circ} \mathrm{C}$ once plasticized with the same amount of DEHP, EMRA, and EFAME, respectively. The plasticizing efficiency of EFAME was much higher than DEHP, simply because the former possessed no bulky moieties as the benzene ring in DEHP. Since the glass transition temperature of EMRA-plasticized PVC was quite close to that plasticized with EFAME, it was concluded that EMRA displayed not only suppressed migration, but also comparable plasticizing efficiency to ordinary EFAME.

\section{Conclusions}

In conclusion, we have demonstrated that a pendant acetate ester group can be covalently attached to epoxidized methyl ricinoleate bio-plasticizer by a simple three-step method. Based on a combined experimental and simulation study, we also conclude that the extent of epoxidation does not constitute the only determinant influencing interaction between EFAME and PVC matrix. Rather, the presence of a short, polar acetate ester protruding from the EFAME chain is more efficient in trapping the bio-plasticizers, and thus, suppressing them from leaching out of the PVC matrix. This strategy circumvents the long-existing limit confronting conventional strategy that highlights the sole contribution of epoxy value to achievable migration resistance, and thus may point the way towards new EFAME alternatives with updated performance to substitute ortho-phthalates for manufacturing PVC artificial material.

\section{Additional file}

Additional file 1: Table S1. Simulated and experimental density ( $\rho)$, cohesive energy density (CED), and Hildebrand solubility parameter $(\sigma)$ of the pure PVC model, well-equilibrated at $300 \mathrm{~K}$ after simulated annealing. Table S2. Glass transition temperature (Tg) of pure PVC, and PVC membranes plasticized with the same amount of DEHP, EMRA, and EFAME. (PDF $86 \mathrm{~kb}$ )
Acknowledgements

We acknowledge the Analytical \& Testing Center of Sichuan University for providing computational resources. 


\section{Authors' contributions}

SP synthesized the EMRA plasticizer, interpreted the data, and was a major contributor in writing the manuscript. DH performed the FT-IR experiment. GY performed the NMR experiment. QX performed the GC-MS experiment. SY determined the acid value, iodine value, hydroxyl number, epoxy value, and flash point of the plasticizer. QZ performed the MD simulation. ZW evaluated the plasticizer exudation level at 0 and $70{ }^{\circ} \mathrm{C}$. YC proposed the technique route to synthesize the EMRA plasticizer, and evaluated the plasticizer extraction loss from the PVC membranes. HF evaluated the fogging value of the plasticized PVC membranes. All authors read and approved the final manuscript.

\section{Funding}

We gratefully acknowledge financial support of this work by National Key Research and Development Program of China (2017YFB0308600), National Natural Science Foundation of China (21878196), and Fundamental Research Funds for the Central Universities, China (20826041C4159).

\section{Availability of data and materials}

All data generated or analysed during this study are included in this published article [and its supplementary information files].

\section{Competing interests}

The authors declare that they have no competing interests.

\section{Author details}

'Key Laboratory of Leather Chemistry and Engineering of Ministry of Education, Sichuan University, Chengdu 610065, People's Republic of China. ${ }^{2}$ National Engineering Laboratory for Clean Technology of Leather Manufacture, Sichuan University, Chengdu 610065, People's Republic of China.

Received: 2 April 2019 Accepted: 3 June 2019

Published online: 29 July 2019

\section{References}

1. Cheng J, Cao Y, Jiang S, Gao Y, Nie J, Sun F. Synthesis and performances of UV-curable polysiloxane-polyether block polyurethane acrylates for PVC leather finishing agents. Ind Eng Chem Res. 2015;54:5635-42.

2. Li M, Li S, Xia J, Ding C, Wang M, Xu L, Yang X, Huang K. Tung oil based plasticizer and auxiliary stabilizer for poly(vinyl chloride). Mater Des. 2017; 122:366-75.

3. Suzuki AH, Botelho BG, Oliveira LS, Franca AS. Sustainable synthesis of epoxidized waste cooking oil and its application as a plasticizer for polyvinyl chloride films. Eur Polym J. 2018;99:142-9.

4. Feng G, Hu L, Ma Y, Jia P, Hu Y, Zhang M, Liu C, Zhou Y. An efficient biobased plasticizer for poly (vinyl chloride) from waste cooking oil and citric acid: synthesis and evaluation in PVC films. J Clean Prod. 2018;189:334-43.

5. Yang $\mathrm{P}$, Sun $\mathrm{H}$, Fan $\mathrm{H}$, Shi B. Novel environmentally sustainable cardanolbased plasticizers: synthesis and properties. Polym Int. 2016;65:464-72.

6. Jia P, Zhang M, Hu L, Feng G, Bo C, Zhou Y. Synthesis and application of environmental castor oil based polyol ester plasticizers for poly (vinyl chloride). ACS Sustain Chem Eng. 2015;3:2187-93.

7. Harte I, Birkinshaw $C$, Jones E, Kennedy J, Debarra E. The effect of citrate ester plasticizers on the thermal and mechanical properties of poly (DLlactide). J Appl Polym Sci. 2013;127:1997-2003.

8. Greco A, Ferrari F, Maffezzoli A. Effect of the epoxidation yield of a cardanol derivative on the plasticization and durability of soft PVC. Polym Degrad Stab. 2016;134:220-6.

9. Chengxiang L, Maolin J, Zhanqun Z, Minzhong Z, Yi C, Haojun F. Application of epoxy fatty acid methyl ester plasticizer in PVC artificial leather. Leather Sci Eng. 2013;4:9-13.

10. Johnson W Jr. Final report on the safety assessment of ricinus communis (castor) seed oil, hydrogenated castor oil, glyceryl ricinoleate, glyceryl ricinoleate se, ricinoleic acid, potassium ricinoleate, sodium ricinoleate, zinc ricinoleate, cetyl ricinoleate, ethyl ricinoleate, glycol ricinoleate, isopropyl ricinoleate, methyl ricinoleate, and octyldodecyl ricinoleate. Int J Toxicol. 2007;26:31-77

11. Plasticizers-Determination of acid value and acidity. Chinese National GB standardization, GB/T 1668-2008.
12. Determinating the iodine value of plasticizers. Chinese National GB standardization, GB/T 1676-2008.

13. Determinating the epoxy value of plasticizers. Chinese National GB standardization, GB/T 1677-2008.

14. Plasticizers-Determination of flash point-Clevelabd open cup method. Chinese National GB standardization, GB/T 1671-2008.

15. Plastics-Polyols for use in the production of polyurethane-Determination of hydroxyl number. International Standard ISO 14900:2001.

16. Rubber- or plastics-coated fabrics-Determination of fogging characteristics of trim materials in the interior of automobiles. International Standard ISO 6452:2000.

17. Determination of the fogging characteristics of trim materials in the interior of automobiles. Deutsches Institut für Normung DIN 75201.

18. Sun H. COMPASS: an ab initio force-field optimized for condensed-phase applications overview with details on alkane and benzene compounds. J Phys Chem B. 1998;102:7338-64.

19. Chang J, Guan X, Chen Y, Fan H. Interfacial regions in spherical nanoparticle-doped glassy polymers: interfaces or interphases? Polym Chem. 2016;7:3398-405.

20. Chen Y, Jia M, Xu H, Cao Y, Fan H. Counterintuitive gas transport through polymeric nanocomposite membrane: insights from molecular dynamics simulations. J Phys Chem C. 2014;118:28179-88.

21. Narwal SK, Saun NK, Dogra P, Chauhan G, Gupta R. Production and characterization of biodiesel using nonedible castor oil by immobilized lipase from bacillus aerius. Biomed Res Int. 2015;9:281934.

22. Knothe $\mathrm{G}$. Some aspects of biodiesel oxidative stability. Fuel Process Technol. 2007:88:669-77.

\section{Publisher's Note}

Springer Nature remains neutral with regard to jurisdictional claims in published maps and institutional affiliations.

\section{Submit your manuscript to a SpringerOpen ${ }^{\circ}$ journal and benefit from:}

- Convenient online submission

- Rigorous peer review

- Open access: articles freely available online

- High visibility within the field

- Retaining the copyright to your article

Submit your next manuscript at $\boldsymbol{\nabla}$ springeropen.com 